\title{
A Multilevel Account of Social Value-Related Reasons behind Mastery Goals
}

\author{
Annique Smeding ${ }^{1}$, Benoît Dompnier ${ }^{2}$, Emanuele Meier $^{3}$, Céline Darnon $^{4}$, and Fabrizio Butera ${ }^{2}$ \\ ${ }^{1}$ Univ. Savoie Mont Blanc, Univ. Grenoble Alpes \\ ${ }^{2}$ University of Lausanne \\ ${ }^{3}$ University of Applied Sciences and Arts of Southern Switzerland \\ ${ }^{4}$ Université Clermont Auvergne, LAPSCO - CNRS UMR6024
}

\begin{abstract}
Author Note
This research was supported by the Swiss National Science Foundation. We would like to thank the schoolteachers, students, and school head for their warm welcome and participation in this study; students from the Haute Ecole Pédagogique Vaud for their help with entering the data; J.C. Quinton for his help in generating and updating the R code for all Figures.

Correspondence concerning this article should be addressed to Annique Smeding, Univ. Savoie Mont Blanc, LIP/PC2S, BP 1104, 73011 Chambéry cedex, France. Email: annique.smeding@univ-smb.fr or to Benoît Dompnier, Université de Lausanne, Géopolis, 1015 Lausanne, Switzerland. Email: Benoit.Dompnier@unil.ch

The data that support the findings of this study are available from the corresponding authors upon reasonable request.
\end{abstract}

Word count: 5'050 


\begin{abstract}
Background: A growing literature focuses on reasons behind achievement goal endorsement, and mastery-approach goals (MG) specifically, and how these reasons influence academic performance. Past research provides evidence that student-level social value-related reasons behind MG moderate the MG-performance link in adolescents and young adults. However, we ignore whether this moderation is best conceived of as a student-level effect (i.e., students' social value-related reasons), a class-level effect (i.e., influence of class-dependent contextual social value), or both.
\end{abstract}

Aims: This research aims at understanding the moderation of the MG-performance link by social value from a multilevel account, which is novel, as the student-level has been the default level so far. Sample: The study was conducted on a sample of 436 primary school students, from $3^{\text {rd }}$ to $6^{\text {th }}$ grade. Methods: Students completed a MG scale adapted to their French classes under different instructions: standard, social desirability (answer to be viewed as likeable by your teacher), social utility (answer to be viewed as successful by your teacher), along with a dictation to measure performance, and sociodemographic measures.

Results: Results show that the moderation effect of social utility on the MG-dictation performance link is observed at the student level, but that the moderation by social desirability is best accounted for by class-level differences.

Conclusions: It is important to consider a multilevel framework when examining reasons behind MG reports, including social value-related reasons, both for future research and teachers in the classroom.

Keywords: mastery-approach goals, social value, school performance, multilevel account, primary school 


\section{A Multilevel Account of Social Value-Related Reasons behind Mastery Goals}

Do students who declare being highly motivated to learn, actually learn and achieve better than those lower in such a motivation? Or is students' self-reported level of mastery goals - the aim to learn and master the task - influenced by underlying reasons behind this report? A theory-driven and empirically robust literature has established that it is crucial to consider the social value-related reasons attached to self-reported mastery goals to understand when they are related to actual performance and when they are not. The present research extends previous studies to a sample of primary school students and provides the first test that disentangles the respective roles of studentlevel and class-level social value reasons by using a multilevel design.

\section{The Underlying Reasons behind Achievement Goals' Self-Reports}

Achievement goal research has established a distinction between mastery goals - with a focus on task- or self-related competence evaluation - and performance goals - with a focus on other- and appearance-related competence evaluation. A distinction has subsequently been made between approach and avoidance goals (Elliot \& McGregor, 2001; Elliot \& Murayama, 2008). Here we focus on mastery-approach goals (hereafter MG) ${ }^{1}$, because of a pervasive and interesting puzzle. Although MG are positively linked to a wealth of adaptive, learning-related outcomes, (e.g., Diseth, 2011; Poortvliet \& Darnon, 2010; Harackiewicz et al., 2002; Senko et al., 2013; Senko et al., 2011; Sideridis \& Kaplan, 2011), an inconsistent and overall rather weak link was found between MG and achievement (Hulleman et al., 2010; Huang, 2012).

Research has thus focused on the reasons behind MG reports: Self-reported MG enlightens what students want to achieve in academic contexts - master the task, improve their learning - but does not inform about why students pursue these goals, that is, about the reasons behind goal endorsement (Sommet \& Elliot, 2017; Vansteenkiste et al., 2014). Reasons behind achievement goals

\footnotetext{
${ }^{1}$ In the $3 \times 2$ framework (Elliot et al., 2011), the classical conceptualization of mastery is set aside. While the $3 \times$ 2 framework offers important clarifications with some respect, its recency and the abandonment of the mastery goal concept altogether make it currently difficult to integrate in the present research. Indeed, the body of literature we rely on has investigated reasons behind mastery-approach goals, but not behind the goals reconceptualized in the $3 \times 2$ framework.
} 
can be examined through the lens of different frameworks (Dompnier et al., 2009; Dompnier et al., 2015; Sommet \& Elliot, 2017; Smeding et al., 2015; Vansteenkiste et al., 2014; Vansteenkiste et al., 2010). Here, we turn to the social value literature to predict when - and for whom - social valuerelated reasons, at different levels of analyses, interact with MG reports to predict school performance.

\section{Self-Reported Mastery Goals in Academic Context: A Social Value Approach}

From a teacher's perspective, promoting MG among students is highly desirable to foster progress and skill acquisition. As a result, MG are highly valued by teachers, and students know this (Darnon et al., 2009). From a student's perspective, this knowledge is adaptive, as students reporting endorsing MG should be positively judged by their teachers on the two fundamental dimensions of social judgment (Abele et al., 2008). These two dimensions, social desirability (or warmth) and social utility (or competence) respectively refer to (a) individuals' ability to satisfy motivations of the members of a social group and the extent to which individuals are liked; (b) individuals' ability to satisfy functional constraints of a given social environment, and the degree to which they can succeed in this environment (Beauvois, 2003; Beauvois \& Dubois, 2009; Pansu \& Dompnier, 2011). Thus, students may report MG in achievement contexts because they perceive them as desirable and/or as a means to succeed.

When it comes to MG self-reports, students, on average, know how to respond to be positively judged on both dimensions in academic contexts (Dompnier et al., 2009, 2015; Smeding et al., 2015). In the self-presentation paradigm (Gilibert \& Cambon, 2003; Jellison \& Green, 1981; Ones \& Viswesvaran, 1998), students complete a scale (here, a MG scale) according to three different instructions: Standard (report your own level of agreement), social desirability (answer the items to be viewed as likeable and popular by your teacher), and social utility (answer the items to be viewed as successful by your teacher). Consistently, average levels of reported MG are higher with social desirability and social utility instructions compared to standard instructions (Darnon et al., 2009; Dompnier et al., 2009; Smeding et al., 2015). Beyond averages, however, students differ in the extent to which they endorse these social value related reasons. Individual differences in underlying reasons result in variations regarding the psychological meaning of MG reports (Dompnier et al., 2013), and are therefore a robust moderator of the MG-performance link. The self-presentation paradigm allows 
empirically assessing social value-related reasons and clarifying the psychological meaning of MG reports for students.

Specifically, a same mean level of spontaneously (i.e., with standard instructions) reported MG does not have the same meaning depending on whether students report these goals to be liked by their teachers (social desirability reasons) and/or to succeed in academic contexts (social utility reasons). While endorsing MG for social desirability reasons would reflect a strategy based on a fake endorsement of these goals, endorsing MG for social utility reasons reflects a genuine commitment with these goals due to their perceived utility to reach success. Thus, level of spontaneously endorsed MG predicts performance, but to the extent that students perceive these goals low in social desirability and high in social utility. These moderations by individual differences in social value related reasons, replicated in different countries, in adolescent and young adult samples (Dompnier et al., 2009; Smeding et al., 2015), have contributed to understand why, on average, the MG-performance link is often weak, with some students truly believing in MG's utility and others reporting them to be liked by teachers.

\section{A Multilevel Account of Social value-related Reasons}

Empirical research conducted so far on this issue has exclusively focused on student-level differences. However, do these effects merely result from student-level differences or may they in part be accounted for by class-level moderation? The student- versus class-level issue is far from being trivial: While student-level moderation may be understood as a specific type of student-level reason behind MG reports (Vansteenkiste et al., 2014), class-level moderation stems from a different, context-dependent level, and is best understood from a social value perspective. Our objective here is to provide a critical test on the origin of the observed moderation effects, by testing both student- and class-level effects through a multilevel account.

From a social value perspective, social desirability and social utility reflect reasons that do not correspond to the same level of analysis: While social utility reasons reflect a students' individual belief regarding the efficacy of MG to reach academic success, social desirability reasons reflect students' adjustment to a specific normative context, created by the teacher in charge of the class. Given that teachers could vary in the way they promote $\mathrm{MG}$ and like students who strongly endorse 
MG, students could vary across classes in the degree to which they endorse these goals to please their teachers (social desirability). We can therefore expect social desirability's moderating effect to be more context-dependent than social utility's moderating effect. Consequently, we expected social desirability and social utility reasons to moderate the link between MG and performance at two distinct levels: a student-level moderation of social utility, because it reflects the extent to which students believe MG are useful for academic attainment (H1); and, since social desirability should be more context-dependent, a class-level moderation (H2). Our target multilevel model thus aimed at simultaneously testing student-level moderation for social utility and class-level moderation for social desirability on the (student-level) MG-performance link.

These moderation hypotheses were tested in primary school for two reasons. First, since past research investigated these moderations at the student-level among high school and university students (Dompnier et al., 2009; Smeding et al., 2015), testing these effects among younger students would provide relevant information about their level of generalization across age groups. Second, contrary to high school and university students, who are confronted with as many teachers as disciplines in their program, primary school students have only one referent teacher during the academic year. In such class context, social desirability's moderation effect should appear as a contextual effect related to the class environment given that students from the same class would like to be appreciated by the same target, that is their common referent teacher.

\section{Present Research}

The study was conducted in a primary school, with students from grade 3 to 6 completing a grade-adapted performance measure, a MG scale adapted to their French classes under standard, social desirability, and social utility instructions, their level in French along with demographics. Preliminary analyses assessed whether the use of multilevel models was required to integrate the nested structure of data. Following an iterative process, main analyses subsequently tested several nested models (i) Model 1, with covariates only, to test the relevance of including several control variables which ought to be meaningfully related to dictation performance (i.e., evidence for criterion-related validity); (ii) Model 2, which additionally included MG under standard instructions (at class- and student-levels) to test classical assumptions of achievement goal research - that is, a direct link between MG and 
performance; (iii) Model 3, which tested our main predictions, and thus additionally included classlevel perceptions of MG social desirability and student-level perceptions of MG social utility; and (iv) Model 4, serving as a final check, which tested the additional moderation effect of student-level perceptions of social desirability, which may be observed independently of its expected class-level moderation.

\section{Method}

\section{Participants}

Data for this cross-sectional study were collected in a single primary school located in a French-speaking Swiss canton at the beginning of the school year (fall). All $3^{\text {rd }}\left(n=101, M_{\text {age }}=8.02\right)$, $4^{\text {th }}\left(n=112, M_{\text {age }}=9.11\right), 5^{\text {th }}\left(n=107, M_{\text {age }}=10.26\right)$ and $6^{\text {th }}\left(n=116, M_{\text {age }}=11.23\right)$ graders were included in the study (for a total of 23 classes), resulting in a total sample of 436 primary school students. The school authorities and teachers approved of the research, and only students who received parental consent participated in the study. However, data for 22 students were excluded from the analyses due to missing data on the dictation test. The final sample was composed of 414 students (196 girls, 217 boys, 1 unreported; $853^{\text {rd }}$ graders, $1084^{\text {th }}$ graders, $1065^{\text {th }}$ graders, and $1156^{\text {th }}$ graders). Sample size was thus determined by the number of students present during data collection. No other data exclusions were applied, and analyses were performed only once data for the entire sample were collected.

\section{Procedure and measures}

Performance measure. As our aim was to have a standardized measure of performance in French which was customary to do for students, assessed learning without requiring specific preparation or homework, a dictation test was a good candidate. To limit students' cognitive fatigue and homogenize test taking duration across classes, participants first completed the dictation in French. Two dictations were used, which varied in difficulty. One was designed for $3^{\text {rd }}$ and 4 th graders, and one for $5^{\text {th }}$ and $6^{\text {th }}$ graders. Because the two dictations were devised based on official learning requirements for, respectively, $4^{\text {th }}$ and $6^{\text {th }}$ graders, they should be more difficult for $3^{\text {rd }}$ and $5^{\text {th }}$ graders, respectively. This choice was made in accordance with schoolteachers and was justified to avoid a ceiling effect which should have limited variance for upper-grade students $\left(4^{\text {th }}\right.$ and $\left.6^{\text {th }}\right)$. A floor 
effect was less likely given the continuous nature of our performance indicator, that is, number of errors on the dictation, with higher values indicating more errors (and thus lower performance). Given these features, part of the variance on dictation performance is expected to be explained by grade level, which will be tested by including grade levels as class-level covariates in the multilevel models. Mastery goal scale under standard, social desirability, and social utility instructions adapted to French classes. After the dictation, students completed, among other measures to prevent suspicion, the validated French version (Darnon \& Butera, 2005) of the MG (approach) subscale of Elliot and McGregor's (2001) achievement-goal scale (3 items, 7-point rating scale; e.g., "to learn as much as possible"). ${ }^{2}$ These items were completed three times: in a standard condition ("indicate your own level of agreement"), always presented first to obtain an uncontaminated measure of a priori endorsement, and then according to two within-participants conditions (order counterbalanced across participants): social desirability ("'indicate your level of agreement (...) with a view to presenting yourself as someone who is likely to be appreciated by your teacher') and social utility ('indicate your level of agreement (...) with a view to presenting yourself to your teacher as someone who is likely to succeed in his or her studies"). Social desirability and utility instructions were those used in previous research (e.g., Dompnier et al., 2009; Smeding et al., 2015) and are fully described as Supporting Information, along with some procedural adaptations for the younger students.

Self-assessment in French and demographics. Upon completion of the main questionnaire, students reported their perceived level in French on an 11-point scale $(0=I$ am very bad at French classes; $10=$ I am very good at French classes). This measure was included to serve as a proxy for academic ability and to control for individual differences in prior achievement level (see Dompnier et al., 2009; Smeding et al., 2015). It will be included as a student-level covariate in the multilevel models and can be expected to be meaningfully related to dictation performance. Students finally reported their age, grade level, and gender.

\section{Results}

\footnotetext{
${ }^{2}$ In addition to mastery goal items, performance goal items (approach and avoidance) were also included in the present study. Since they were not relevant for the present project and given the number of factors already included in our focal Model, these additional items were not included for analytical purposes.
} 
Preliminary analyses and variable treatment. $\mathrm{R}$ software was used for data processing and estimation, with appropriate packages for multilevel models (nlme, emmeans). We performed a series of preliminary analyses which supported the use of multilevel models to adequately integrate the nested structure of data collected on the dictation $(\mathrm{ICC} 1=.30)$. Based on these models, we extracted withinclass residuals for student-level predictor variables (MG scores under the three types of instructions, and self-assessments in French, all centered on their respective class/group means) to remove the betweenclass component and avoid redundancy in the residuals. We also computed two aggregated class-level variables for which reliability indicators could be considered as satisfactory (Lance et al., 2006). Indeed, consistent with the theoretical distinction we propose between social desirability and social utility reasons, MG under social desirability instructions showed between-class variability $(\operatorname{ICC} 1=.12)$ whereas MG under social utility did not $(\mathrm{ICC} 1=.01)$. A class-level predictor for MG under social desirability instructions was thus created (ICC2 $=.71$ ). In addition, since MG under standard instructions showed between-class variability $(\mathrm{ICC} 1=.13)$, a class-level predictor based on this variable was also computed $(\mathrm{ICC} 2=.73)$. No class-level predictor was computed for MG under social utility instructions given low reliability $(\mathrm{ICC} 2=.16)$. This preliminary analyses thus provide support to our theoretical rationale: Social utility reasons, with no associated between-class variability, seem to reflect individuallevel beliefs, whereas social desirability reasons are context-dependent. A full description of these preliminary analyses is provided as Supporting Information.

Model with covariates only (Model 1). Overall, analyses supported the relevance of this covariates-only model, which included three level 2 variables - one to contrast grades $3 / 4(-1)$ with grades $5 / 6(+1)$, one to contrast grade $3(-1)$ with grade $4(+1)$, one to contrast grade $5(-1)$ with grade $6(+1)$ - and one level 1 variable, namely, residuals for self-assessments in French. Results showed a better fit for the model with level 2 and level 1 covariates compared to a model without covariates (likelihood ratio test), $\chi 2(4)=146, p<.0001$. In addition, the relevant level 2 and level 1 covariates meaningfully accounted for part of the variation observed on the focal criterion - number of errors - 
and were retained as covariates in subsequent models. ${ }^{3}$ An extended version of the results pertaining to Model 1 is provided as Supporting Information.

Model adding $M G$ under standard instructions only (Model 2). This model aimed at testing a classical assumption of MG, that is, a direct link between MG and performance. This model included the aforementioned covariates plus MG under standard instructions, at the student and class levels to adequately model the nested structure of the data. This model hence tested whether mere MG endorsement - at the student and class levels - was sufficient to account for students' dictation performance. Results showed that, besides the aforementioned covariates - which remained significant predictors of performance (as in Model 1) - neither MG at the student-level, $t(387)=-1.71, p=.09$, nor MG at the class level were significantly related to number of errors, $t(18)=0.74, p=.47$. The interaction between student-level and class-level MG was not significant either, $t(387)=-0.75, p=$ .46. Consistently, model comparison did not indicate a better fit for Model 2 as compared to Model 1 (including covariates only), $\chi 2(4)=5.94, p=.20$.

Focal model for hypothesis testing (Model 3). Model 3 was our focal model regarding the hypothesized moderating roles of MG social value. We therefore additionally entered, at the studentlevel, MG under social utility instructions, and at the class-level, MG under social desirability instructions, along with relevant two- and three-way interactions. In accordance with the theoretical rationale, Model 3 was designed to test the moderating role of MG under social desirability instructions at the class level (focal interaction between student-level MG under standard instructions and class-level MG under social desirability instructions), and the moderating role of MG under social utility instructions at the student-level (focal interaction between student-level MG under standard instructions and social utility instructions), along with relevant interactions. Table 1(class-level) and Table 2 (student-level) report correlations for variables of this Model 3, and Table 3 results of the multilevel analyses.

\footnotetext{
${ }^{3}$ The use of performance-related covariates is common practice in educational psychology - and even consensual for some (e.g., Marks, 2021) - because it absorbs meaningful variance on the DV and allows proper examination of other variables net of pre-existing individual differences. We partitioned variance using a linear model for Model 1 . Results indicate that $43 \%$ of variance was explained by these four covariates and, importantly, distributed as follows: $18 \%$ for contrast grades 3 vs. 4, 14\% for self-assessments in French, $6 \%$ for contrast grades $3 / 4$ vs. $5 / 6$, and $5 \%$ for contrast grades 5 vs. 6 .
} 
Besides the covariates, which remained significantly related to dictation performance, adding the aforementioned student and class-level variables in Model 3 resulted in a significant effect of MG under standard instructions at the student level, $t(381)=-1.99, p<.05, d=-.18$, signaling less errors when level of MG increases (effect sizes correspond to an equivalent of Cohen's $d$ ). More importantly regarding moderation, this student-level relationship was moderated by MG reported under social utility instructions at the student level, $t(381)=-2.39, p<.05, d=-.22$, as predicted in $\mathrm{H} 1$. To further examine this two-way interaction, we estimated simple slopes at different meaningful values of the moderator. These analyses reveal that the negative link between level of MG under standard instructions and number of errors was significant for students perceiving this goal as high in social utility ( $+1 \mathrm{SD}), b=-2.83, t(381)=-3.09, p<.01$, but not for those perceiving this goal as low in social utility $(-1 \mathrm{SD}), b=-.01, t(381)=-.01, p=.99$. Thus, at the student-level, perceiving MG as socially useful allowed students to benefit, in terms of dictation performance, from higher levels of MG reported under standard instructions. These findings are reported in Figure 1.

In addition to this student-level two-way interaction, results indicate that student-level MG under standard instructions were moderated by class-level MG under social desirability instructions, $t(381)=2.18, p<.05, d=0.67$, as predicted in H2. Further examining this student-level by class-level two-way interaction effect, analyses signal that the negative link between MG under standard instructions and number of errors was significant in classes where this goal was perceived as low in social desirability $(-1 \mathrm{SD}), b=-3.19, t(381)=-2.68, p<.01$, but not in classes where this goal was perceived as high in social desirability $(+1 \mathrm{SD}), b=.34, t(381)=.36, p=.72$. Students thus benefit, in terms of dictation performance, from higher levels of MG under standard instructions if they belong to classes where these goals are perceived as low in social desirability. These findings are reported in Figure 2. Finally, a three-way interaction effect indicates that this two-way interaction depended on class-level perceptions of MG under standard instructions, $t(381)=2.21, p<.05, d=1.17$. More precisely, it is only in classes where MG are highly endorsed (+1SD) that the moderation by classlevel endorsement under social desirability instructions is significant, $b=9.12, t(381)=2.56, p<.05$, and not in classes where MG are endorsed to a lower extent (-1SD), $b=1.62, t(381)=.71, p=.48$. Results are reported in Figure 1 of the Supporting Information. Model comparison indicates a better fit 
for Model 3 as compared to Model 2, $\chi 2(8)=19.2, p<.05$, signaling the relevance of including the aforementioned moderators.

Final check (Model 4). This model tested whether adding student-level perceptions of MG social desirability did account for additional variance on number of errors, that is, over and above the focal moderators included in Model 3. Results are detailed as Supporting Information and signal that perceptions of social desirability at the student level did not have an additional moderation effect to the one observed at the class level.

\section{Discussion}

The present research aimed at examining the moderation effects of social value on the MGperformance link at the class- and student-levels. It hence offers a multilevel account of a phenomenon previously conceptualized and tested at the student (individual)-level only. Our focal multilevel model simultaneously tested class-level moderation for social desirability and student-level moderation for social utility on the (student-level) MG-performance link. Through iterative model comparisons, the main results attest the relevance of taking class- and student-level variables into consideration when examining moderation of the MG-performance link by social value-related reasons. Consistent with expectations, social utility moderation is best conceived of at the student-level and social desirability moderation at the class-level, with no additional moderation of student-level perceptions of social desirability.

Extending previous findings in other samples, results replicate the student-level moderation effect of social utility on the MG-performance link at the primary school level: As predicted in H1, higher (versus lower) student-level perceptions of social utility allowed students to benefit from high MG endorsement. Endorsing MG for reasons pertaining to their usefulness for academic success thus supports performance, as early on as primary school. Regarding moderation by social desirability, the present findings are of primary importance as they operate at the class-level only: As predicted in $\mathrm{H} 2$, lower (as opposed to higher) class-level (but not student-level) perceptions of MG social desirability allowed students to benefit, in terms of performance, from high MG endorsement. A three-way interaction revealed that this is especially the case if MG were also high at the class level. This result sheds new light on previous conceptualizations pertaining to reasons behind MG reports, stemming 
both from social value and goal complexes approaches, where the student-level account used to be the default (Dompnier et al., 2009; Sommet \& Elliot, 2017; Smeding et al., 2015). Given this student-level effect in past research, we also tested the additional moderation effect of student-level perceptions of social desirability. Findings do not support this pattern, indicating that among primary school students, the moderating effect of MG social desirability on the MG - performance link depended more on class contexts than on students' individual differences in perceived MG social desirability.

This result is not surprising given that in primary school only one teacher is in charge of all students of the same class during the year. In such context, between-class variabilities of MG social desirability can be considered as differences in the class climate created by each referent teacher: Classes with high(low) level of MG social desirability may indicate that their respective teacher appreciate more(less) students who endorse MG. Thus, depending on these class climates, students from the same class would be encouraged to a higher or lower extent to report endorsing MG for social desirability reasons, possibly without any genuine MG pursuit. Although not predicted a priori, the fact that the moderating effect of MG social desirability was stronger in classes that reported high level of MG endorsement is in line with this reasoning. On the one hand, MG predicted performance on the dictation test only when the class climate did not encourage MG for self-presentation purposes and when on average students strongly endorsed MG. On the other hand, classes in which MG were highly socially desirable and highly endorsed, students' individual MG endorsement was emptied of its psychological meaning, leading to a loss of its association with performance.

Results provide important guidance for teachers and educators: In their classroom, starting at an early age, they may convey the message that it is important to be motivated to learn and to progress because this fosters learning opportunities and achievement. They can do so either by telling students to endorse MG or by structuring the classwork so that what is really expected is that students progress and learn (i.e., goal structure, Meece et al., 2006). The present research suggests that the first option may be counterproductive because it could encourage students to endorse MG for the wrong reasons (social desirability). Organizing classroom work to encourage student engagement in learning for the sake of learning itself (e.g., rewarding progress instead of performance per se) - and not to gain the teacher's favor - may therefore be a more sustainable option. These educational implications are 
important given that moderation effects were found on a sound and ecological behavioral measure of test performance. This was confirmed by analyses supporting criterion-related validity (i.e., pertaining to the grade-level and self-assessments variables) for dictation performance, with improvement from one grade to another which should stem from skill acquisition throughout the years. Although an emphasis on performance per se might be considered somewhat limiting, the importance of performance as an outcome - both for students' future opportunities, and as a behavioral measure more difficult to bias than self-reports - is real (see also Senko, 2016). We therefore suggest that future research, in particular when it comes to other types of reasons behind MG reports, should pay particular attention to also include performance measures, and to incorporate the multilevel account offered by social value research to span a fuller range of reasons behind MG endorsement.

Notwithstanding the present research's contributions, limitations should be highlighted. First, although $\mathrm{H} 2$ predicted a class-level moderation for social desirability reasons, the observed three-way interaction revealed that this was especially the case if $\mathrm{MG}$ were also high at the class level (i.e., under standard instructions). This finding seems to signal the importance of classroom goal structures, a point that has been made by others (Meece et al., 2006). This result should be replicated in future studies and, in such an endeavor, it may be important to also include measures adapted from previous research focusing, for instance, on identifying instructional practices (e.g., Ames, 1992). This would allow pairing such practices with the explanatory power of class-level MG-related moderators in a multilevel model and help understanding why they impact the MG-achievement link.

Second, the dictation test was completed before the students reported MG with the different instructions. This procedure was preferred to the opposite order (MG first followed by the dictation) to limit students' fatigue, homogenize test taking duration across classes, and thus have an uncontaminated performance measure. Although perceived success on the dictation may have some influence on level of reported goals, goals measured or manipulated before the critical performance measure can certainly affect this outcome (see Van Yperen et al. 2015, for a meta-analysis on the impact of situationally induced achievement goals). As in our design, MG had to be reported three times during the same session, the risk of contaminating the critical performance measure therefore existed. In addition, and of critical importance, the present research should be fully considered in light 
of previous studies on which the present one is based (Dompnier et al., 2009, 2015; Smeding et al., 2015). Indeed, this past research either manipulated the social value associated with mastery goals or measured these goals several weeks or months before the final performance measure. The present results are both in line and extend these previous findings, supporting their robustness to procedural variations. Therefore, although the specific findings of the present study are limited in terms of generalizability - as all variables were focused on the French language domain - when included in the broader literature on social value-related reasons behind mastery goals, procedural variations do not seem to threaten the results pattern.

\section{Conclusion}

The present research adds a new stone to the growing literature on reasons behind achievement goals, and behind mastery(-approach) goals more specifically. Focusing on social-value related reasons behind MG from a student-level and class-level account, the present research shows that the previously observed moderation by social utility and social desirability on the MGperformance link is observed early on, namely in primary school. Moreover, concerning social desirability in classroom settings, this moderation does not seem to result from student-level differences, which has been the default level of analysis thus far, but may be better accounted for by class-level differences. At a basic level, this highlights the importance of considering a multilevel framework when examining reasons behind MG reports. At the applied level, this provides important guidance for teachers as to how best promote MG in their classrooms to foster motivation and performance, namely, not by trying to convince their students that they would like them to endorse MG, but rather by structuring their class so that these goals (mastering the task and improving one's ability) appear as a prerequisite for reaching success. 


\section{References}

Abele, A. E., Cuddy, A. J., Judd, C. M., \& Yzerbyt, V. Y. (2008). Fundamental dimensions of social judgment. European Journal of Social Psychology, 38, 1063-1065. doi: 10.1002/ejsp.574

Ames, C. (1992). Classrooms: goals, structures, and student motivation. Journal of Educational Psychology, 84, 261-71. doi:10.1037/0022-0663.84.3.261

Beauvois, J.-L. (2003). Judgment norms, social utility, and individualism. In N. Dubois (Ed.), $A$ sociocognitive approach to social norms (pp. 123-147). London: Routledge.

Beauvois, J. L., \& Dubois, N. (2009). Lay psychology and the social value of persons. Social and Personality Psychology Compass, 3, 1082-1095. doi: 10.1111/j.1751-9004.2009.00225.x

Darnon, C., \& Butera, F. (2005). Buts d'accomplissement, stratégies d'étude et motivation intrinsèque : Présentation d'un domaine de recherche et validation française de l'échelle d'Elliot et McGregor (2001) [Achievement goals, study strategies, and intrinsic motivation: Presenting a domain of research and the French validation of Elliot \& McGregor's (2001) scale]. L'Année psychologique, 105, 105-131. doi: 10.3406/psy.2005.3821

Darnon, C., Dompnier, B., Delmas, F., Pulfrey, C., \& Butera, F. (2009). Achievement goal promotion at university: social desirability and social utility of mastery and performance goals. Journal of Personality and Social Psychology, 96, 119-134. doi: 10.1037/a0012824

Diseth, $\AA$. (2011). Self-efficacy, goal orientations and learning strategies as mediators between preceding and subsequent academic achievement. Learning and Individual Differences, 21, 191-195. doi: 10.1016/j.lindif.2011.01.003

Dompnier, B., Darnon, C., \& Butera, F. (2009). Faking the desire to learn: A clarification of the link between mastery goals and academic achievement. Psychological Science, 20, 939-943. doi:10.1111/j.1467-9280.2009.02384.x

Dompnier, B., Darnon, C., \& Butera, F. (2013). When performance-approach goals predict academic achievement and when they do not: A social value approach. British Journal of Social Psychology, 52, 587-596. doi:10.1111/bjso.12025 
Dompnier, B., Darnon, C., Meier, E., Brandner, C., Smeding, A., \& Butera, F. (2015). Improving low achievers' academic performance by changing the social value of mastery goals. American Educational Research Journal, 52, 720-749. doi: 10.3102/0002831215585137

Dweck, C. S. (1986). Motivational processes affecting learning. American Psychologist, 41, 10401048. doi:10.1037/0003-066X.41.10.1040

Elliot, A. J. (2005). A conceptual history of the achievement goal construct. In A. J. Elliot \& C. Dweck (Eds.), Handbook of competence and motivation (pp. 52-72). New York, NY: The Guilford Press.

Elliot, A. J., \& McGregor, H. A. (2001). A $2 \times 2$ achievement goal framework. Journal of Personality and Social Psychology, 80, 501-519. doi: 10.1037/0022-3514.80.3.501

Elliot, A. J., \& Murayama, K. (2008). On the measurement of achievement goals: Critique, illustration, and application. Journal of Educational Psychology, 100, 613-628. doi: $10.1037 / 0022-0663.100 .3 .613$

Elliot, A. J., Murayama, K., \& Pekrun, R. (2011). A $3 \times 2$ achievement goal model. Journal of Educational Psychology, 103, 632-648. doi: 10.1037/a0023952

Gilibert, D., \& Cambon, L. (2003). Paradigms of the sociocognitive approach. In N. Dubois (Ed.), $A$ sociocognitive approach to social norms (pp. 38-69). London: Routledge.

Harackiewicz, J. M., Barron, K. E., Tauer, J. M., \& Elliot, A. J. (2002). Predicting success in college: A longitudinal study of achievement goals and ability measures as predictors of interest and performance from freshman year through graduation. Journal of Educational Psychology, 94, 562-575. doi:10.1037/0022-0663.94.3.562

Huang, C. (2012). Discriminant and criterion-related validity of achievement goals in predicting academic achievement: A meta-analysis. Journal of Educational Psychology, 104, 48-73. doi: $10.1037 / \mathrm{a} 0026223$

Huang, C. (2016). Achievement goals and self-efficacy: A meta-analysis. Educational Research Review, 19, 119-137. doi: j.edurev.2016.07.002 
Hulleman, C. S., Schrager, S. M., Bodmann, S. M., \& Harackiewicz, J. M. (2010). A meta-analytic review of achievement goal measures: Different labels for the same constructs or different constructs with similar labels? Psychological Bulletin, 136, 422. doi: 10.1037/a0018947

Jellison, J. M., \& Green, J. (1981). A self-presentation approach to the fundamental attribution error: The norm of internality. Journal of Personality and Social Psychology, 40, 643-649. doi: $10.1037 / 0022-3514.40 .4 .643$

Lance, C. E., Butts, M. M., \& Michels, L. C. (2006). The sources of four commonly reported cutoff criteria: What did they really say? Organizational Research Methods, 9, 202220. doi: $10.1177 / 1094428105284919$

Marks, G. N. (2021). Should value-added school effects models include student-and schoollevel covariates? Evidence from Australian population assessment data. British Educational Research Journal, 47, 181-204. doi: 10.1002/berj.3684

Meece, J. L., Anderman, E. M., \& Anderman, L. H. (2006). Classroom goal structure, student motivation, and academic achievement. Annual Review of Psychology, 57, 487-503. doi: 10.1146/annurev.psych.56.091103.070258

Nicholls, J. G. (1984). Achievement motivation: Conceptions of ability, subjective experience, task choice, and performance. Psychological Review, 91, 328-346. doi: 10.1037/0033295X.91.3.328

Ones, D. S., \& Viswesvaran, C. (1998). The effects of social desirability and faking on personality and integrity assessment for personnel selection. Human Performance, 11, 245-269. doi: $10.1080 / 08959285.1998 .9668033$

Pansu, P., \& Dompnier, B. (2011). A bidimensional scale of scholastic value: Social desirability and social utility, two dimensions of personological judgment. European Review of Applied Psychology, 61, 31-41. doi: 10.1016/j.erap.2010.08.001

Poortvliet, M., \& Darnon, C. (2010). Towards a more social understanding of achievement goals: The interpersonal effects of mastery and performance goals. Current Directions in Psychological Science, 19, 324-328. doi:10.1177/0963721410383246 
Senko, C. (2016). Achievement goal theory. Handbook of motivation at school, 75.

Senko, C., Hama, H., \& Belmonte, K. (2013). Achievement goals, study strategies, and achievement. A test of the "learning agenda" framework. Learning and Individual Differences, 24, 1-10. doi: 10.1016/j.lindif.2012.11.003

Senko, C., Hulleman, C. S., \& Harackiewicz, J. M. (2011). Achievement goal theory at the crossroads: Old controversies, current challenges, and new directions. Educational Psychologist, 46, 2647. doi:0.1080/00461520.2011.538646

Sideridis, G. D., \& Kaplan, A. (2011). Achievement goals and persistence across tasks: The roles of failure and success. The Journal of Experimental Education, 79, 429-451. doi: $10.1080 / 00220973.2010 .539634$

Smeding, A., Dompnier, B., Meier, E., Darnon, C., Baumberger, B., \& Butera, F. (2015). The motivation to learn as a self-presentation tool among Swiss high school students: The moderating role of mastery goals' perceived social value on learning. Learning and Individual Differences, 43, 204-210. doi: 10.1016/j.lindif.2015.08.036

Sommet, N., \& Elliot, A. J. (2017). Achievement goals, reasons for goal pursuit, and achievement goal complexes as predictors of beneficial outcomes: Is the influence of goals reducible to reasons? Journal of Educational Psychology, 109, 1141-1162. doi: 10.1037/edu0000199

Vansteenkiste, M., Lens, W., Elliot, A. J., Soenens, B., \& Mouratidis, A. (2014). Moving the achievement goal approach one step forward: Toward a systematic examination of the autonomous and controlled reasons underlying achievement goals. Educational Psychologist, 49, 153-174. doi: 10.1080/00461520.2014.928598

Vansteenkiste, M., Mouratidis, A., \& Lens, W. (2010). Detaching reasons from aims: Fair play and well-being in soccer as a function of pursuing performance-approach goals for autonomous or controlling reasons. Journal of Sport \& Exercise Psychology, 32, 217-242. doi: 10.1123/jsep.32.2.217

Van Yperen, N. W., Blaga, M., \& Postmes, T. (2014). A meta-analysis of self-reported achievement goals and nonself-report performance across three achievement domains (work, sports, and education), PloS One, 9, e93594. 
Van Yperen, N. W., Blaga, M., \& Postmes, T. (2015). A meta-analysis of the impact of situationally induced achievement goals on task performance. Human Performance, 28, 165-182. doi: $10.1080 / 08959285.2015 .1006772$ 


\section{Figure 1}

Dictation performance as a function of student-level mastery goals with standard instructions and student-level mastery goals with social utility instructions, with 95\% confidence bands. The lower the error score, the better the performance

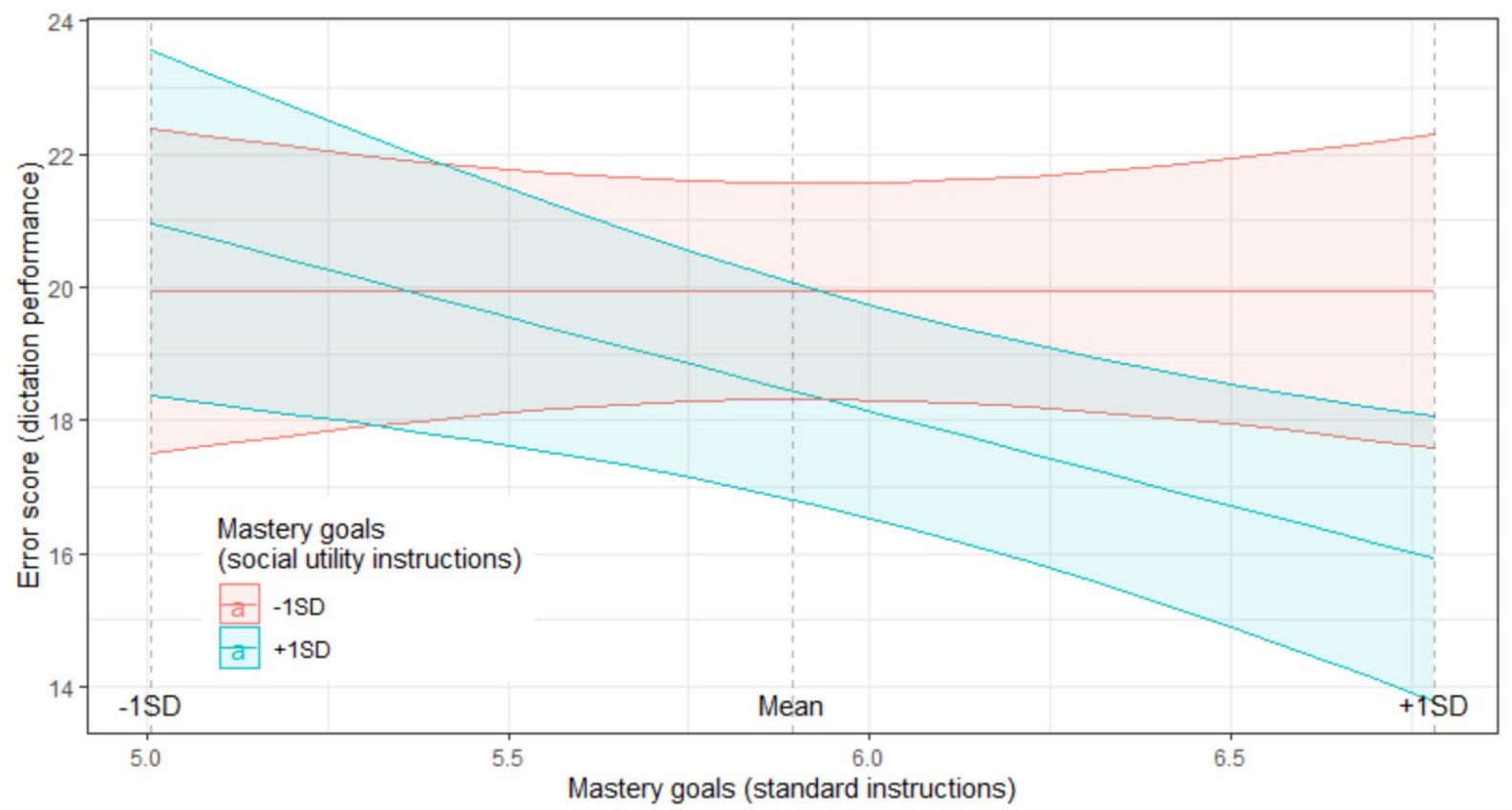

\section{Figure 2}

Dictation performance as a function of student-level mastery goals with standard instructions and class-level mastery goals with social desirability instructions, with 95\% confidence bands. The lower the error score, the better the performance

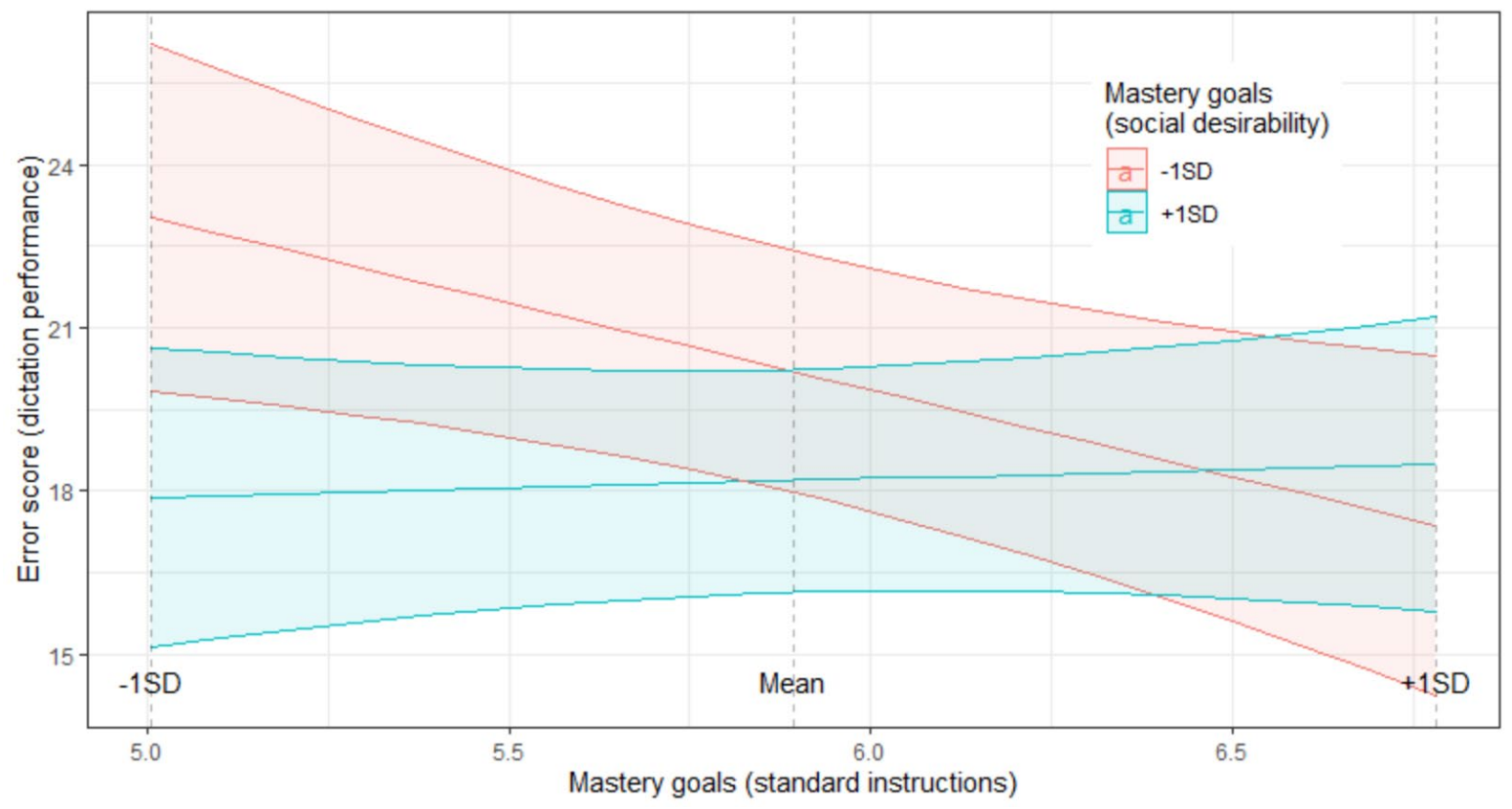




\section{Table 1}

Correlations for Class-Level Variables $(N=23)$

\begin{tabular}{lccccccc}
\hline Predictors & $M$ & $S D$ & ContGrades & ContGrad34 & ContGrad56 & MG & MGSD \\
\hline MG & 5.89 & 0.40 & $-.73^{* *}$ & .06 & -.21 & - & - \\
MGSD & 6.37 & 0.33 & $-.80^{* *}$ & .06 & -.20 & $.82^{* *}$ & - \\
\hline
\end{tabular}

Note. ContGrades contrasts grades 3/4 (-1) with grades 5/6 (+1), ContGrad34 contrasts grade $3(-1)$ with grade $4(+1)$, ContGrad56 contrasts grade $5(-1)$ with grade $6(+1), M G=$ mastery goals standard instructions, MGSD = mastery goals social desirability instructions. $* *$ p $<.01$

\section{Table 2}

Correlations for Student-Level Variables $(N=414)$

\begin{tabular}{lcccccc}
\hline Predictors & $M$ & $S D$ & 1 & 2 & 3 & 4 \\
\hline 1.SelfAssFrench & 7.12 & 1.92 & - & & \\
2.MG & 5.89 & 0.97 & $.43^{* *}$ & - & & \\
3.MGSD & 6.37 & 0.82 & $0.24^{* *}$ & $0.47^{* *}$ & - & \\
4.MGSU & 6.54 & 0.82 & $0.24^{* *}$ & $0.32^{* *}$ & $0.50^{* *}$ & - \\
\hline
\end{tabular}

Note. SelfAssFrench = student-level self-assessments in French, MG = mastery goals standard instructions, MGSD = mastery goals social 
desirability instructions, MGSU $=$ mastery goals social utility instructions. $* * p<.01$ 


\section{Table 3}

Results of the Focal Multilevel Model (Model 3) Predicting Error Scores on Dictation, Including Relevant Class-Level (Level 2) and Student-Level (Level 1 Within-Class Residuals) Variables

\begin{tabular}{|c|c|c|c|c|c|}
\hline Variables & $b / \beta$ & $S E$ & $D f$ & $t$ & $p$ \\
\hline \multicolumn{6}{|l|}{ Class-level (CL) } \\
\hline Contrast grades $3 / 4$ vs. $5 / 6$ & $-3.50 /-.32$ & .73 & 16 & -4.83 & $<.001$ \\
\hline Contrast grades 3 vs. 4 & $-7.24 /-.45$ & .60 & 16 & -12.13 & $<.001$ \\
\hline Contrast grades 5 vs. 6 & $-3.58 /-.24$ & .64 & 16 & -5.62 & $<.001$ \\
\hline Mastery Goals Standard (CL-MGS) & $2.01 / .07$ & 1.92 & 16 & 1.05 & .31 \\
\hline Mastery Goals Social Desirability (CL-MGSD) & $-3.05 /-.09$ & 2.53 & 16 & -1.21 & .25 \\
\hline \multicolumn{6}{|l|}{ Student-level (SL) } \\
\hline Residuals self-assessments (SL-SA) & $-1.95 /-.34$ & .24 & 381 & -8.13 & $<.001$ \\
\hline Residuals Mastery Goals Standard (SL-MGS) & $-1.42 /-.12$ & .71 & 381 & -1.99 & .05 \\
\hline
\end{tabular}




\begin{tabular}{|c|c|c|c|c|c|}
\hline Residuals Mastery Goals Social Utility (SL-MGSU) & $-.92 /-.07$ & .63 & 381 & -1.45 & .15 \\
\hline \multicolumn{6}{|l|}{ actions } \\
\hline SL-MGS x CL-MGS & $-2.25 /-.07$ & 2.02 & 381 & -1.11 & .27 \\
\hline SL-MGS x CL-MGSD & $5.37 / .15$ & 2.46 & 381 & 2.18 & .03 \\
\hline CL-MGS x CL-MGSD & $-1.96 /-.02$ & 3.53 & 16 & -.56 & .59 \\
\hline SL-MGS x SL-MGSU & $-1.73 /-.19$ & .73 & 381 & -2.39 & .02 \\
\hline SL-MGS x SL-SA & $.10 / .02$ & .24 & 381 & .40 & .69 \\
\hline SL-MGSU x SL-SA & $.13 / .02$ & .28 & 381 & .47 & .64 \\
\hline SL-MGS x CL-MGS x CL-MGSD & $9.31 / .13$ & 4.22 & 381 & 2.21 & .03 \\
\hline SL-MGS x SL-MGSU x SL-SA & $-.41 /-.14$ & .23 & 318 & -1.77 & .08 \\
\hline
\end{tabular}

